\title{
TRANSFORMAÇÕES RECENTES NO COMÉRCIO E CONSUMO: AS TROCAS DE MERCADORIAS A PARTIR DO FACEBOOK NA CIDADE DE PELOTAS-RS
}

\author{
Patrícia da Cruz Oliveira \\ Doutoranda no Programa de Pós-graduação em Geografia da Universidade Estadual Paulista "Júlio de \\ Mesquita Filho" - Campus Rio Claro (Unesp/Rio Claro) \\ patricia ufpel@hotmail.com
}

\begin{abstract}
RESUMO
O trabalho refere-se às mudanças recentes no âmbito do comércio e consumo, e teve como objetivo central a análise de novas relações de trocas de mercadorias a partir da intrínseca relação entre os espaços virtual e concreto. Foi construído em três momentos: 1) discussão sobre o contexto atual, marcado pela hipermodernidade e as Tecnologias da Informação e Comunicação (TICs); 2) considerações sobre comércio e consumo, em especial o e-commerce; e, 3) estudo de caso sobre as trocas realizadas a partir do Facebook na cidade de Pelotas-RS, através dos grupos de trocas de mercadorias e de quatro eventos organizados e divulgados, em grande medida, através do Facebook: a "Feira do Rolo", o "Fotroca", o "Piquenique Cultural" e o "Sofá na Rua". Através de questionários aos participantes dos grupos de trocas, entrevistas com os organizadores dos eventos, visitas aos eventos, pesquisa bibliográfica e pesquisa no Facebook, constatou-se a importância das TICs e dos Sites de Redes Sociais (SRS) nas relações de trocas atuais, bem como em seus desdobramentos no uso e ocupação dos espaços públicos urbanos. Pretende-se, assim, contribuir para o avanço das análises das trocas de mercadorias realizadas atualmente na perspectiva do comércio e do consumo na área de Geografia Urbana.
\end{abstract}

Palavras-chave: Sites de Redes Sociais. Tecnologias da Informação e Comunicação. E-commerce. Espaços Públicos Urbanos.

\section{RECENT TRANSFORMATIONS IN TRADE AND CONSUMPTION: THE TRADE OF GOODS FROM FACEBOOK IN THE CITY OF PELOTAS-RS}

\begin{abstract}
The work refers to the recent changes in the scope of trade and consumption, and had as its central objective the analysis of new relations of trade of goods from the intrinsic relation between virtual and concrete spaces. It was built in three moments: 1) discussion about the current context, marked by hypermodernity and Information and Communication Technologies (ICTs); 2) trade and consumption considerations, especially e-commerce; and, 3) a case study on the exchanges made from Facebook in the city of Pelotas-RS, through the merchandise exchange groups and four events organized and publicized, largely through Facebook: "Feira do Rolo", "Fotroca", "Piquenique Cultural" and "Sofá na Rua". Through of questionnaires to participants of the exchange groups, interviews with event organizers, visits to events, bibliographic research and research on Facebook, the importance of TICs and Social Networking Sites (SNS) was verified in the current exchange relationships, as well as its unfolding in the use and occupation of urban public spaces. It is intended, therefore, to contribute to the advancement of the analyzes of merchandise exchanges currently carried out from the perspective of trade and consumption in the area of Urban Geography.
\end{abstract}

Keywords: Social Network Websites. Information and Communication Technologies. E-commerce. Public and Urban Spaces.

\section{INTRODUÇÃO}

O presente artigo é resultado de uma pesquisa de mestrado que buscou investigar e analisar algumas das transformações em curso relacionadas especialmente às relações de comércio e consumo, ou de trocas materiais que envolvem a troca de dinheiro por serviços e/ou mercadorias 
(produto do trabalho, que possui valor de uso e valor de troca, passíveis de serem compradas e/ou vendidas, ou mesmo trocadas por outras mercadorias). Também estarão presentes nesta investigação as relações de trocas imateriais, as quais podem ser entendidas como aquelas em que não estão presentes materialidades, nem dinheiro e nem mercadorias. Ou seja, aquelas que envolvem trocas de informações, de técnicas, de conhecimentos etc. Tem dessa maneira, como objetivo central, a análise de novas relações de trocas de mercadorias a partir da intrínseca relação entre os espaços virtual e concreto.

O comércio, de modo geral entendido aqui como troca voluntária de mercadorias e/ou serviços por dinheiro (e vice-versa), apresenta novas estratégias e formas no período atual, nas quais se destaca o e-commerce (ou comércio eletrônico). Este traz consigo novas relações de consumo, que neste artigo trata-se da prática econômica de adquirir mercadorias e/ou serviços, e novas relações espaciais por dispor de dinâmicas diferentes daquelas encontradas nas formas comerciais tradicionais (lojas, mercados, supermercados etc.). Por exemplo, não é necessário que o consumidor se desloque até o local onde a mercadoria está, ou mesmo não é necessário que exista uma estrutura física de venda de mercadorias direta ao consumidor. No entanto, para que o comércio e o consumo se realizem nesta forma ou estratégia comercial, é imprescindível que os envolvidos disponham do aparato tecnológico necessário, como acesso à Internet e a computadores.

Nesse sentido, partimos do pressuposto que vivemos um tempo marcado pela velocidade e fluidez nas mais diversas relações que constituem a vida moderna, possibilitadas em grande medida pela ascensão das Tecnologias da Informação e Comunicação (TICs). Desta ascensão presenciamos o surgimento e a interação entre dois espaços que por vezes se complementam: o virtual e o concreto - este último relacionado ao espaço físico que comporta a materialidade necessária ao espaço virtual -, e que levantam novos questionamentos e possibilitam novas interpretações, referentes tanto às relações sociais quanto às relações espaciais.

Assim primeiramente investigamos o período atual, o surgimento das TICs e o desenvolvimento do ciberespaço (LÉVY, 1999), bem como a relação entre o virtual e o real, ou atual (LÉVY, 2011). Em seguida, a pesquisa centrou-se nas atualizações das formas comerciais das empresas e em suas estratégias comerciais. Nesta altura foram priorizados os estudos referentes ao e-commerce, que vem se destacando a partir do aumento do uso da Internet e das TICs, proporcionado tanto pelo uso do computador quanto, mais recentemente, pelo smartphone. Nesse sentido, ao qual o cotidiano tem sido cada vez mais marcado pela presença das TICs, seja nas formas comerciais ou nas próprias relações sociais, observa-se o uso acentuado dos Sites de Redes Sociais (SRS) como o Facebook e o Instagram por exemplo. Desse modo, considerando o papel de destaque dos SRS no contexto atual, verificamos no Facebook um aspecto particularmente importante nesta investigação: sua participação nas relações de comércio e consumo.

Tal participação é encontrada especialmente através de três situações distintas. A primeira referese à abertura de espaços específicos no Facebook para o marketing das empresas. A segunda é aquela surgida a partir da possibilidade de criação de grupos destinados às trocas de mercadorias entre os seus usuários. E a terceira refere-se à utilização deste SRS enquanto ferramenta para a organização de eventos por seus usuários, como feiras e encontros em espaços públicos urbanos, que também possibilitam a troca de mercadorias. Essas duas últimas situações merecem especial atenção, visto que são pensadas, organizadas e administradas especialmente pelos próprios usuários do Facebook, a partir deste SRS e, por esse motivo, foram escolhidas para um estudo de caso na cidade de Pelotas-RS, que compõe o último momento da pesquisa realizada.

Dessa forma, o texto foi construído em três momentos centrais para além da introdução, dos resultados e discussões e das considerações finais: 1) discussão sobre o contexto atual, marcado pela hipermodernidade e as Tecnologias da Informação e Comunicação (TICs); 2) considerações sobre comércio e consumo, em especial o e-commerce, e; 3) estudo de caso sobre as trocas realizadas a partir do Facebook na cidade de Pelotas-RS, através dos grupos de trocas de mercadorias e de quatro eventos organizados e divulgados em grande medida através do Facebook: a "Feira do Rolo", o "Fotroca", o "Piquenique Cultural" e o "Sofá na Rua".

Para a obtenção dos dados foram utilizados como técnicas a aplicação de questionários online através do Google Docs (ferramenta gratuita online que permite ao usuário criar "formulários" que podem ser compartilhados vitualmente através de um link de acesso) em 84 grupos de trocas do 
Facebook identificados com mais de 1.000 membros cada (foram identificados 116 grupos com mais 1.000 membros. No entanto, em 32 deles não foi permitido aplicar o questionário, de acordo com as regras dos grupos e dos seus respectivos administradores), o que resultou em 126 questionários respondidos; entrevistas semi-estruturadas com os(as) quatro organizadores(as) dos eventos pesquisados; visitas em uma das edições dos dois eventos investigados com maior número de edições realizadas: "Sofá na Rua" e "Piquenique Cultural"; pesquisa bibliográfica acerca do tema e dos eventos investigados; e pesquisa nos grupos de trocas e nos grupos e nas páginas dos eventos investigados presentes no Facebook.

Considerando as rápidas mudanças presenciadas a partir do advento das TICs, pretende-se com essa pesquisa contribuir para o avanço das análises das relações atuais de trocas de mercadorias, realizadas através do espaço virtual e seus desdobramentos no espaço geográfico, especialmente na perspectiva do comércio e do consumo na área de Geografia Urbana.

\section{A HIPERMODERNIDADE COMO CONDIÇÃO PARA TRANSFORMAÇÕES DAS RELAÇÕES SOCIAIS: AS TICS, O VIRTUAL E OS SRS}

Nas últimas décadas do século XX houve significativas mudanças globais, num período histórico marcado pelo aprofundamento das bases que erigiram a Modernidade, e que propiciaram condições materiais e imateriais para as transformações que aqui serão exploradas. Trata-se do advento da Hipermodernidade (LIPOVETSKY e CHARLES, 2004), no qual a sociedade presenciou modificações especialmente pelos avanços tecnológicos e científicos que, dentre outras características, proporcionaram ressignificações do tempo e do espaço.

As movimentações financeiras, as relações de comércio e consumo e interpessoais podem ir além das ações espaciais fixas e dos tempos predeterminados: as ações podem ultrapassar barreiras espaciais que antes representariam obstáculos difíceis de transpor, e o tempo não constitui um problema, de modo que as ações podem ser tomadas a milhares de quilômetros a qualquer hora do dia ou da noite, instantaneamente. No entanto, é necessário destacar que os fixos espaciais continuam exercendo um papel central, especialmente na infraestrutura do espaço virtual, pois constituem o suporte físico indispensável para a sua realização, o que pode determinar o alcance e efetividade das ações estabelecidas através das TICs.

Ademais, tal perspectiva de mudanças a nível global é apresentada tanto por Lipovetsky (2004) quanto por Ascher (2010) e Mitchell (2002), sendo que este último assinala mudanças em pelo menos três aspectos na vida urbana relacionadas às TICs. Em primeiro lugar, as mudanças na vida em sociedade; em seguida, as mudanças na vida cotidiana, nas relações e ritmos diários; e por fim, as mudanças nas formas e velocidade de comunicação na troca de conhecimentos. Para Ascher (2010) nos encontramos na terceira modernidade, a qual aponta para uma sociedade mais racional, mais individualista e mais diferenciada, com elementos de uma modernização reflexiva, com novos avanços científicos e o uso acrescido das ciências e das técnicas, resultando também numa sociedade do risco. Sociedade esta que apresenta uma autonomia crescente em relação às condicionantes espaciais e temporais, bem como uma individualização cada vez mais marcante e uma diferenciação social cada vez mais complexa; e na qual destaca-se também a passagem de um capitalismo industrial a um capitalismo cognitivo, a partir do fim do futuro previsível e planificável, de uma nova economia do conhecimento, da informação e mais urbana; e, ainda, o aparecimento de uma sociedade hipertexto, possibilitada através de novos tipos de ligações sociais, de uma estrutura social em rede e de uma multiplicidade de pertenças sociais.

No que tange às configurações espaciais, ao longo da história as cidades sempre tiveram elementos relacionados aos avanços tecnológicos sendo inseridos sucessivamente em suas dinâmicas espaciais. Atualmente são inseridos também nas estratégias comerciais e de serviços, como o "Uber", o "Airbnb", o "Waze", por exemplo, destacando o papel das TICs e da Internet. Sua constituição compreendeu um processo contínuo, interativo e alimentado de diversas fontes, privadas ou públicas, individuais ou coletivas (LÉVY, 1999), que acabaram por formar o ciberespaço não totalizável que temos, em constante expansão, do qual o espaço virtual é um dos elementos resultantes e constituintes. Ciberespaço entendido por Levy $(1999$, p. 17) como "novo meio de comunicação que surge da interconexão mundial dos computadores", de modo que tal termo não se restringe a "apenas a infraestrutura material da comunicação digital, mas também o 
universo oceânico de informações que ela abriga, assim como os seres humanos que navegam e alimentam esse universo".

Mas e o que constitui o virtual? Para Lévy (1999, p. 49) "a palavra 'virtual' pode ser entendida em ao menos três sentidos: o primeiro, técnico, ligado à informática, um segundo corrente e um terceiro filosófico". Quanto ao sentido filosófico, o virtual consiste em uma importante dimensão da realidade, pode-se dizer que ele existe mesmo que não esteja fisicamente presente naquele momento, de modo que refere-se àquilo "que existe apenas em potência e não em ato [...]. O virtual encontra-se antes da concretização efetiva ou formal (a árvore está virtualmente presente no grão)" (LÉVY, 1999, p. 49, grifo do autor). Em suma, diz que virtual é "toda entidade 'desterritorializada', capaz de gerar diversas manifestações concretas em diferentes momentos e locais determinados, sem contudo estar ela mesma presa a um lugar ou tempo em particular" (LÉVY, 1999, p. 49). Em outras palavras, "ainda que não possamos fixa-lo em nenhuma coordenada espaçotemporal, o virtual é real. [...] O virtual existe sem estar presente" (LÉVY, 1999, p. 50).

Assim, encontramos significativos elementos da relação espaço-tempo presente nas características da hipermodernidade, visto que o ciberespaço "encoraja um estilo de relacionamento quase independente dos lugares geográficos (telecomunicações, telepresença) e da coincidência dos tempos (comunicação assíncrona)" (LÉVY, 1999, p. 51). O que também é constatado por Harvey (2004) a partir da década de 1960, através do conceito de compressão espaço-temporal, que está relacionado à "aceleração do ritmo da vida, ao mesmo tempo que venceu as barreiras espaciais em tal grau que, por vezes, o mundo parece encolher sobre nós" (HARVEY, 2004, p. 219). Presenciamos, desse modo, uma "intensa fase de compressão do tempo-espaço que tem tido um impacto desorientador e destrutivo sobre as práticas político-econômicas, sobre o equilíbrio do poder de classe, bem como sobre a vida social e cultural" (HARVEY, 2004, p. 257), que intensificase a partir da consolidação do ciberespaço.

Mesmo considerando a importância do espaço virtual na atualidade, é igualmente importante destacar que entende-se que o ciberespaço está ligado intimamente ao espaço geográfico que, para Santos (2002, p. 21), se define em linhas gerais "como um conjunto indissociável de sistemas de objetos e de sistemas de ações". Toda infraestrutura necessária para a existência do ciberespaço está localizada em determinados pontos do espaço, nos "lugares geográficos", sendo sua existência condicionada a materialidade espacial, física. Dessa forma, o que concebemos aqui como espaço físico ou espaço concreto diz respeito ao espaço que comporta a materialidade necessária ao espaço virtual, ou seja, refere-se ao próprio espaço geográfico. Não busca-se, assim, contrapor espaço virtual ao espaço concreto, apenas diferenciá-lo em sua realização.

Desse modo, são cada vez mais evidentes as ações e relações entre e a partir do espaço virtual, ou ciberespaço, e o espaço físico, concreto. Da mesma forma que observamos mecanismos cada vez mais eficientes de controle, sejam nos espaços de decisão ou nos espaços de realização das ações. Nesse sentido, os SRS apresentam papel ímpar atualmente, sendo apropriados e utilizados de diversas maneiras por seus usuários. Os SRS, segundo Recuero (2009, p. 102), "são os espaços utilizados para a expressão das redes sociais na Internet", em linhas gerais tratam-se de "uma categoria do grupo de softwares sociais, que seriam softwares com aplicação direta para a comunicação mediada por computador" (RECUERO, 2009, p. 102, grifo do autor). O caso mais significativo que temos atualmente é o Facebook. Lançado em 2004, este SRS já contava no ano de 2017 com um número de usuários ativos mensais de 2 bilhões ao redor do mundo, conforme anunciado por Mark Zuckerberg, criador do Facebook, em sua página neste SRS em 26 de julho de 2017, passando a atingir a marca de 2,41 bilhões em agosto de 2019 (STATISTA, 2019). Nesse sentido, para além de sua função inicial, a de construir e manter redes e relações sociais no ambiente virtual, o Facebook tem se destacado também como um espaço propício para as relações de trocas de mercadorias.

\section{O TEMPO EFÊMERO E A VELOCIDADE DAS MUDANÇAS NO COMÉRCIO E NO CONSUMO: O E-COMMERCE E O FACEBOOK}

Dentre as inovações no comércio varejista, concebidas através das estratégias por parte das empresas, algumas destacaram-se devido ao impacto na sociedade e no espaço, e também à mudança de hábitos do consumidor: as lojas de departamento, os supermercados e 
hipermercados, os shoppings centers, as franquias e, mais recentemente, o comércio eletrônico ou e-commerce (ORTIGOZA e RAMOS, 2003). Quanto a este último, três pontos destacam-se: a) corresponde a uma nova relação entre o consumidor e a loja; b) resulta na eliminação da necessidade do consumidor se deslocar para realizar suas compras; e, c) reflete em uma maior comodidade e segurança, no sentido de evitar uma maior exposição aos transtornos urbanos (ORTIGOZA e RAMOS, 2003).

O e-commerce, nesse sentido, tornou-se uma das mais eficazes estratégias que levam os consumidores a comprarem sem saírem de casa. Utilizando as TICs, em especial a Internet, apresenta-se hoje como um dos maiores potenciais na esfera dos negócios, considerando a rápida expansão do acesso a essas tecnologias. Em linhas gerais, pode envolver diferentes intermediadores e agentes diversos, como "consumidores, vendedores, comparadores, buscadores, provedores, prestadores de serviço, gestoras de pagamento, compras coletivas, bancos e administradoras de cartão de crédito" (TEIXEIRA, 2015, p. 15).

Sobre o seu surgimento, no que se refere à venda varejista, verificamos que este se deu nos Estados Unidos, com a criação da Amazon.com em 1994, e o lançamento do seu site em 1995, cuja principal vantagem em relação à loja física era "a eliminação de estoques, na medida em que repassa os pedidos de compra diretamente às editoras, reduzindo substancialmente os custos em relação às lojas físicas" (PARAISO, 2011, p. 04). No Brasil, segundo Paraiso (2011) o setor apresenta maior desenvolvimento por volta dos anos 2000, de modo que desde então há um crescimento contínuo.

Atualmente, identifica-se a existência de variações nos tipos de e-commerce, tratados como modelos de negócios online, dos quais destacam-se: 1) o B2C, business to consumer, que são os negócios partindo de empresas para consumidores finais. Trata-se do varejo online, como é o caso da Amazon e de outras empresas que dispõem de um site para vender suas mercadorias diretamente aos consumidores; 2) o $\mathrm{B} 2 \mathrm{~B}$, business to business, ou negócios entre empresas: ocorre quando uma empresa comercializa um software e/ou tecnologia com outra, ou mesmo quando essa tecnologia é utilizada para a produção de uma mercadoria, por exemplo. Ou seja, neste tipo de negócio não há o envolvimento do consumidor final; e, 3) o C2C, consumer to consumer, que são os negócios entre consumidores finais. Um exemplo deste modelo de negócio online pode ser encontrado no Mercado Livre, pois funciona como uma plataforma em que os indivíduos comercializam as suas próprias mercadorias entre si (CATALANI et al., 2004). Ainda, para além dos modelos de negócios online, podemos encontrar outras variações, conforme a tecnologia utilizada e o serviço oferecido. Dentre eles o Social Commerce, ou Comércio Social; o TCommerce, ou Comércio Televisivo; Mobile Commerce, ou M-Commerce; e o FacebookCommerce, ou F-Commerce - que pode abranger três possibilidades: a) estimulador de vendas; b) Pré-venda; e, c) Venda completa (FELIPINI, 2015). É preciso destacar que mesmo aquelas empresas que não vendem diretamente pela Internet, praticamente todas utilizam "a rede de alguma forma: para divulgação, para contato com clientes, para compras e interação com fornecedores, entre outras aplicações" (CATALANI et al., 2004, p. 18), como é o caso do Facebook e outros SRS, por exemplo.

Nesse sentido, a partir de observações empíricas em páginas criadas pelo Facebook e em grupos de troca, compra e venda de mercadorias criadas pelos usuários do Facebook, realizadas ao longo dos anos de 2014, 2015 e 2016, foi possível reconhecer os três modelos de negócios online. Neste SRS foram identificadas modificações realizadas para aprimorar o desempenho relativo ao comércio de mercadorias e serviços de empresas e de indivíduos, sobre os quais dois pontos destacaram-se: a) as ferramentas inseridas para facilitar as relações comerciais, direcionadas tanto para empresas como para indivíduos: os recentemente desenvolvidos plug-ins de compra e venda, como o "Meu Shopping", "Comprar Agora" e "Loja", por exemplo; e, b) O estímulo por parte do Facebook para as empresas aderirem os espaços oferecidos para fins de marketing e e-commerce: páginas e aplicativos específicos, como a página "Facebook para empresas".

Além dessas modificações, que foram desenvolvidas através do próprio SRS, os espaços e situações de trocas criadas e organizadas diretamente entre os seus usuários referem-se a duas situações específicas. Primeiramente, aos grupos de trocas, como "classificados", "compra, venda e troca", "desapegos", "bric", "brechó" etc.. Nestes grupos os membros podem comprar, vender e/ou trocar mercadorias, oferecer serviços e fazer anúncios, sem a presença de intermediários. Cada 
grupo possui dinâmica própria, de acordo com os seus administradores, que podem estabelecer regras e normas específicas. O número de membros em cada grupo é variável, podendo ser encontrados grupos de trocas com mais de cem mil membros e outros com menos de cem, por exemplo. Outra situação de trocas diz respeito aos eventos, que podem ser de tipos diversos, sendo muitos deles essencialmente de cunho cultural. Estes são em grande medida criados, organizados e divulgados através do Facebook por indivíduos, grupos e/ou coletivos em que as trocas, materiais ou não, estão inseridas direta ou indiretamente em suas dinâmicas, sendo realizados em espaços públicos das cidades em que ocorrem, corroborando com a ideia de íntima relação do espaço virtual e do espaço concreto, em que a materialidade espacial é essencial. Tais eventos surgem juntamente com outras formas de movimentos sociais organizados pela sociedade civil a partir dos SRS, que podem ser observados em várias partes do mundo.

A partir do exposto, o Facebook proporciona um espaço para que os seus membros mantenham tanto relações sociais quanto econômicas, direta ou indiretamente. Assim, chama especial atenção os grupos e os eventos criados e organizados neste SRS por seus membros com o intuito de trocar mercadorias, pelo fato de que essas se efetivarão no espaço concreto, mesmo que a princípio se deem no ciberespaço (no caso daquelas trocas combinadas primeiramente no SRS através dos grupos, no caso dos eventos somente há relação de trocas durante a realização dos mesmos), e que tais relações sejam realizadas em uma mesma cidade ou região. Há, dessa forma, uma intensa relação entre o espaço virtual e o espaço concreto a partir das relações de trocas, as quais incitam a análise em perspectiva local a partir de um mecanismo global. Nesse sentido, realizamos um estudo de caso na cidade de Pelotas-RS referente às relações de trocas estabelecidas nos grupos e nos eventos que iniciam-se no Facebook, mas que se concretizam nos espaços públicos desta cidade.

\section{DO FACEBOOK À CIDADE DE PELOTAS-RS: OS EVENTOS E OS GRUPOS DE TROCAS NAS RELAÇÕES DE COMÉRCIO E CONSUMO}

Pelotas é um município da região sul do estado do Rio Grande do Sul, distante $250 \mathrm{~km}$ de Porto Alegre, possui uma população de 328 mil habitantes (IBGE, 2010), sendo a terceira cidade mais populosa desse estado. No campo do ensino, para além do nível básico, conta com pelo menos uma universidade federal (Universidade Federal de Pelotas - UFPel), um instituto federal (Instituto Federal de Educação, Ciência e Tecnologia - IFSul-rio-grandense), uma universidade privada (Universidade Católica de Pelotas - UCPel) e uma faculdade privada (Faculdade Anhanguera). Também economicamente exerce papel de centralidade na região sul do estado, particularmente no setor terciário, apresentando-se como uma importante cidade média brasileira.

Nesta cidade são encontrados os dois tipos de relações de trocas de interesse desta pesquisa, que tem o Facebook como elemento central enquanto ferramenta de organização: os eventos e os grupos de trocas. Destaca-se que ambos podem ser encontrados em diversas cidades pelo país de forma similar, não constituindo exclusividade desta cidade, mas que em Pelotas tem apresentado continuidade e expressividade, conforme demonstrado a seguir.

\section{Os Eventos em Pelotas}

Quanto aos eventos, em Pelotas identificamos quatro experiências com dinâmicas distintas, mas que além de serem gratuitos e com práticas marcadamente de cunho cultural, apresentam pelo menos três pontos centrais comuns: 1) são criados, organizados e divulgados em grande medida através do Facebook; 2) concretizam-se em espaços públicos urbanos, como parques, praças e ruas; e, 3) possuem relações de trocas, sejam elas materiais ou imateriais. São eles a "Feira do Rolo - Pelotas", o "Fotroca", o "Piquenique Cultural" e o "Sofá na Rua", que foram investigados a partir da coleta de dados através de suas páginas e/ou perfis no Facebook, além de visitas em algumas das suas edições e da aplicação de um questionário aos organizadores, em que a ideia central era caracterizá-los a partir dos seus objetivos, locais de ocorrência, ano de criação e número de edições, assim como das dinâmicas das relações de trocas presentes em cada uma delas e outras informações. 


\section{"Feira do Rolo - Pelotas"}

Funcionando através da exposição das mercadorias dos participantes através da montagem de bancas individuais ao ar livre no local previamente escolhido e determinado pela organizadora, a "Feira do Rolo - Pelotas" constitui um evento não itinerante de trocas de mercadorias. Segundo a organizadora, o evento iniciou as suas atividades no ano de $2012 \mathrm{com}$ o nome de "Feira Mercado das Pulgas". Cerca de dois anos depois a Prefeitura Municipal de Pelotas iniciou um projeto semelhante: "Mercado das Pulgas", que resultou em um ano de união de ambos os projetos, os quais separaram-se em janeiro de 2015 e, a partir daí, nasceu a "Feira do Rolo - Pelotas". De acordo com a página do evento no Facebook, a "Feira do Rolo" tem por objetivo "ser um espaço para o público em geral poder trocar e vender peças de roupas e acessórios", que "na nova remodelação vem com o objetivo de se tornar uma feira exclusiva de vestuário em Pelotas, contando com a participação de estilistas e marcas de roupas e acessórios da cidade e região". Em sua descrição, traz que "buscando a conscientização do consumo, a feira veio como um meio de promover a sustentabilidade por trocas e vendas de peças que não estão sendo utilizadas". Destaca ainda que "o evento não tem objetivo de ser um comércio e, sim, uma maneira de fazer com que o ciclo da roupa não acabe no descarte".

Figura 1 - Página da "Feira do Rolo - Pelotas" no Facebook

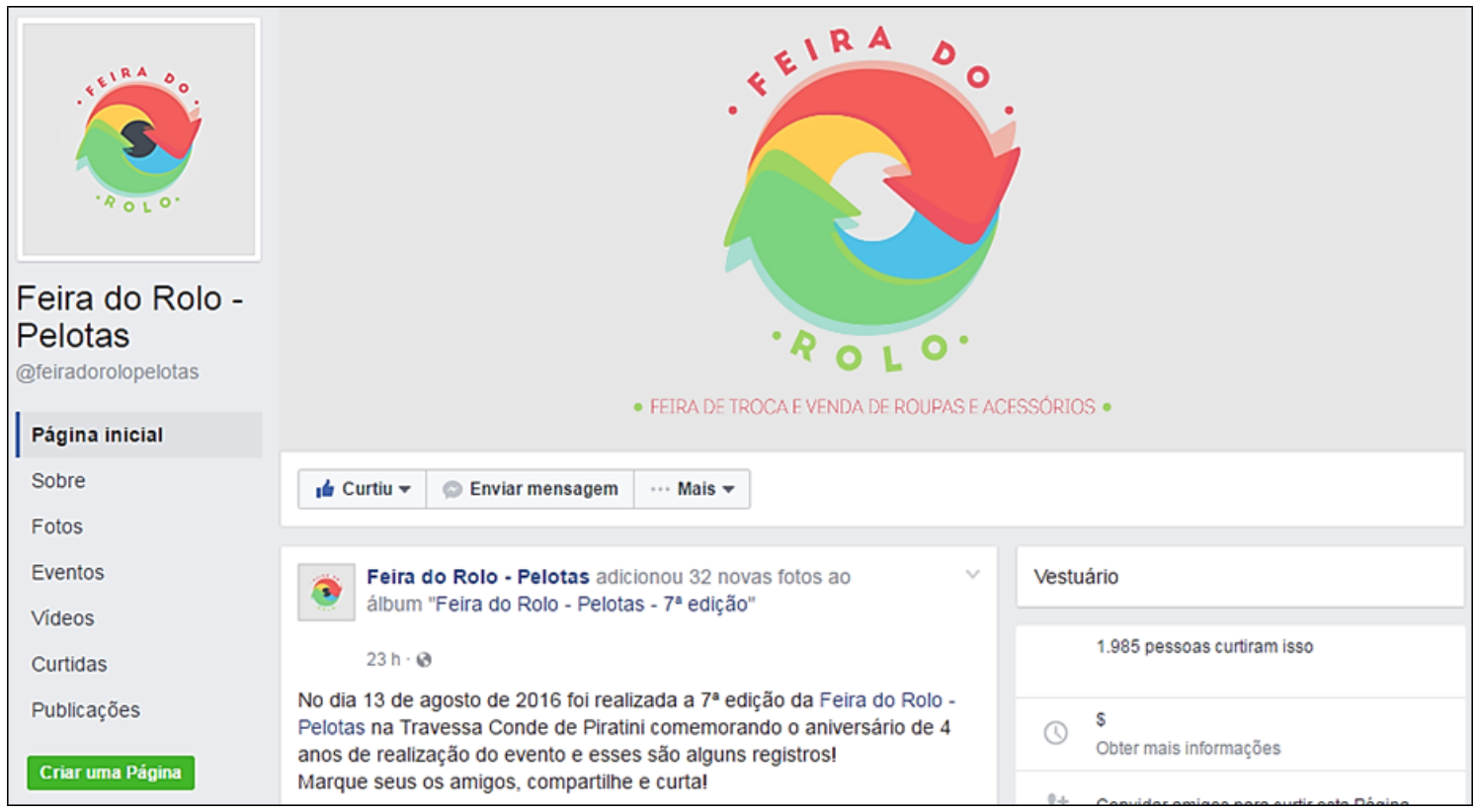

Fonte: Facebook. Disponível em https://www.facebook.com/feiradorolopelotas/ Data: 30 ago. 2016.

\section{“Fotroca"}

O "Fotroca" é um evento independente que teve a sua primeira edição em Pelotas no ano de 2014, mas que é organizado e realizado também por outros grupos em cidades como Santos-SP, Rio de Janeiro-RJ, Belo Horizonte-MG e São Paulo-SP (cidade onde a ideia do evento nasceu e tornou-se inspiração para sua realização na cidade gaúcha, conforme destacou um dos três organizadores do evento realizado em Pelotas). Neste evento a ênfase recai sobre a troca, material no que tange a fotografia impressa, e/ou imaterial, em relação às técnicas, informações e/ou conhecimentos entre os fotógrafos e demais participantes. O objetivo do evento, bem como sua dinâmica, "não é a prática de nenhuma atividade comercial", conforme destaca um dos organizadores, pois trata-se de "reunir fotógrafos amadores, profissionais, estudantes e simpatizantes para interagir sobre o tema Fotografia e cada um trazer uma foto de sua autoria no tamanho $20 \times 30$ para expor num varal e no final fazer uma troca entre os participantes". 
Figura 2 - Página do "Fotroca - Fotoclube Satolep Zoom" no Facebook

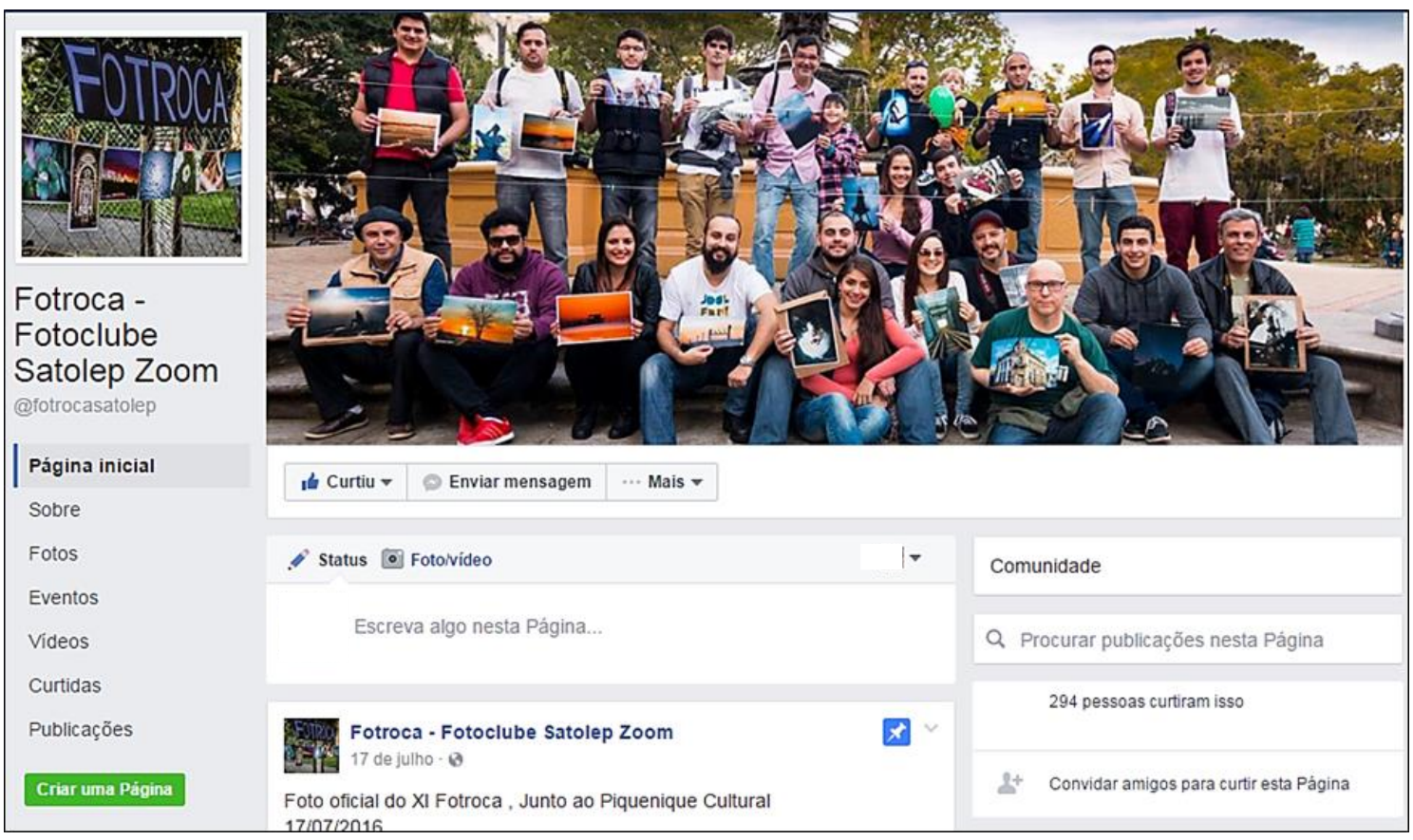

Fonte: Facebook. Disponível em https://www.facebook.com/fotrocasatolep/ Data: 26 ago. 2016.

\section{"Piquenique Cultural"}

Trata-se do mais antigo evento independente investigado. Teve a sua primeira edição no ano de 2010 na cidade de Pelotas e, conforme aponta Mafaldo (2013, p. 14), "no primeiro ano do evento, passaram pelo Piquenique Cultural mais de três mil pessoas e cerca de 50 atrações artísticas diferentes, a proposta de lazer ao ar livre, gratuito, itinerante e voltado para a comunidade recebeu o apoio de pelo menos 43 empresas, projetos e instituições". É um evento itinerante que propõe a ocupação dos espaços públicos com atividades artísticas e culturais, possibilitando também as mais diversas trocas, materiais e imateriais. Participam das edições do evento artistas convidados e independentes, artesãos, culinaristas, estudantes, agentes culturais e sociais, entre outros, que utilizam esse espaço para divulgar, distribuir e/ou comercializar as suas mercadorias ou o seu trabalho. Constitui-se, desse modo, como um "movimento multiartístico que acontece em praças e parques de Pelotas/RS desde 2010", conforme sua descrição no Facebook, na qual destaca-se também que "se configura como uma espécie de feira de oportunidades para a área da cultura, promovendo a formação e integração de redes de trabalho que tendem a ser colaborativas e solidárias".

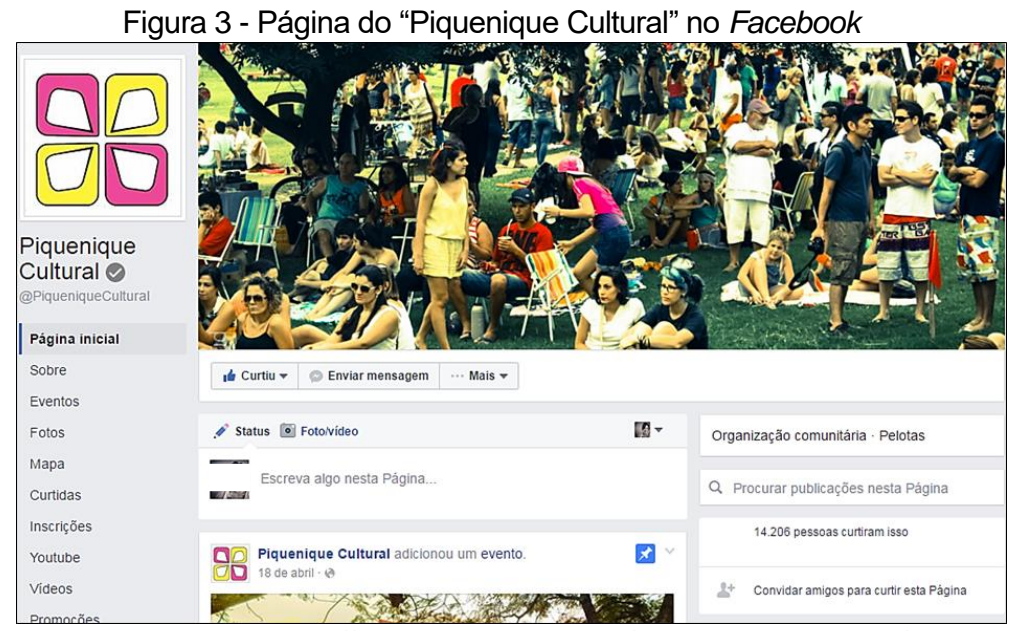

Fonte: Facebook. Disponível em https://www.facebook.com/PiqueniqueCultural/Data: 26 ago. 2016. 


\section{“Sofá na Rua”}

O "Sofá na Rua" é um evento não itinerante que iniciou as suas atividades em 2012, combinando vários tipos de atrações, especialmente aquelas ligadas à cultura, e que vem concentrando um grande e variado público. No Facebook o evento é descrito por seus organizadores como "uma ocupação realizada pela Casa Fora do Eixo Pelotas em parceria com diversos coletivos e pessoas que se apropriam da rua Almirante Tamandaré com música, teatro, cinema, economia colaborativa, debates, oficinas e qualquer intervenção cultural ou artística espontânea". De acordo com uma das organizadoras o evento reúne aproximadamente duas mil pessoas em cada edição. Ainda, identificamos a reprodução do "Sofá na Rua", realizado primeiramente na cidade de Pelotas, em pelo menos outros cinco estados: em Blumenau-SC, em São João del Rei-MG, em Rio do Sul-SC, em São Paulo-SP e em Jaboatão dos Guararapes-PE. Conforme explica uma das organizadoras do "Sofá na Rua" de Pelotas, algumas dessas cidades realizaram edições regulares do evento, como foi o caso de Blumenau-SC, de São Paulo-SP e de Rio do Sul-SC. Além disso, a organizadora nos explica também que essa reprodução do evento ocorre em forma de rede, visto que há uma relação e articulação próxima entre os organizadores das edições nas diferentes cidades em que ocorrem, e que essa relação e articulação se dão em parte através do Facebook.

Figura 4 - Página do "Sofá na Rua" de Pelotas-RS no Facebook

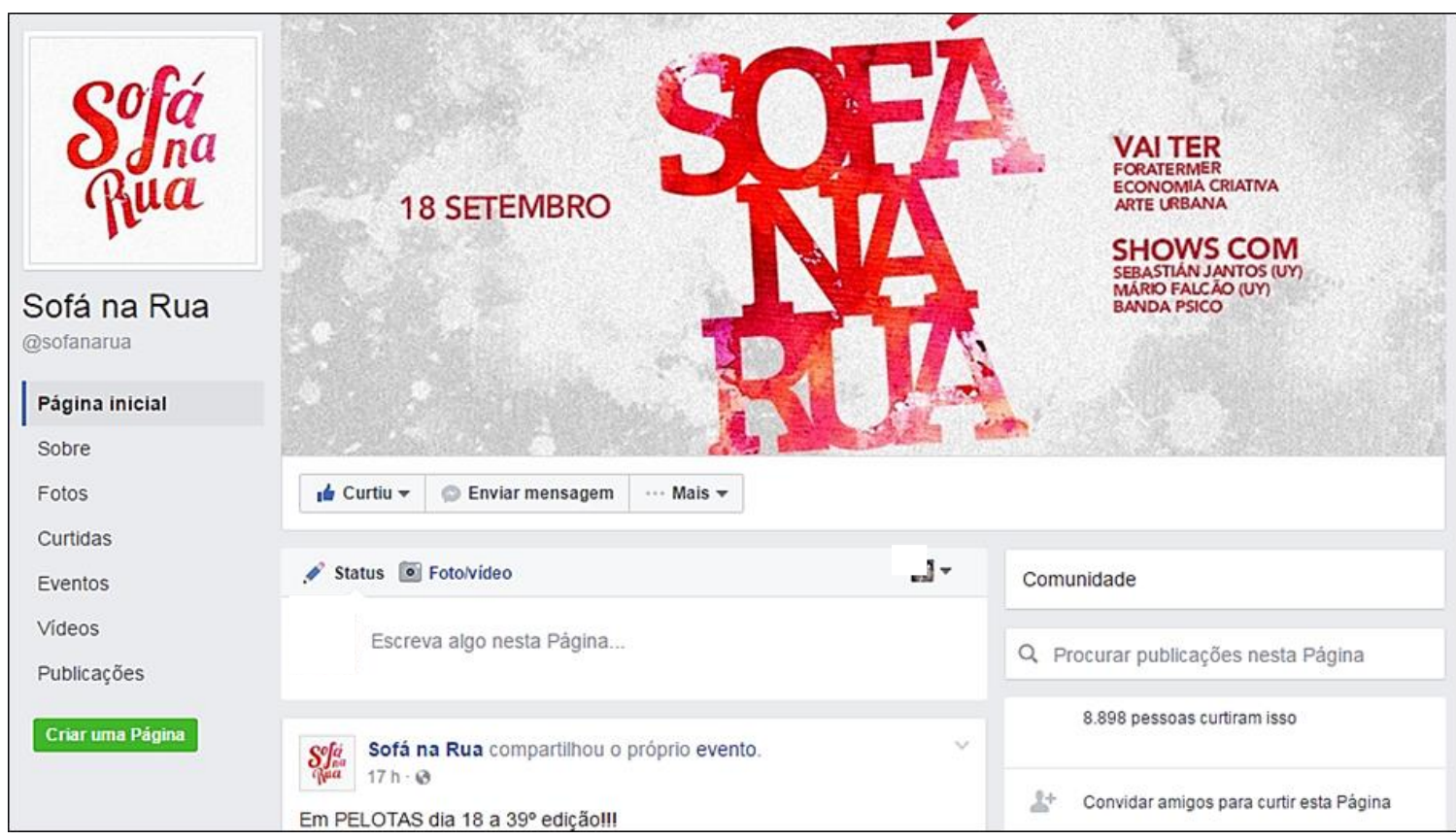

Fonte: Facebook. Disponível em https://www.facebook.com/sofanarua/

Data: 07 set. 2016.

Por fim, para além do ano em que cada evento iniciou as suas atividades, o Quadro 1 apresenta informações quanto ao número de edições de cada evento, bem como os locais de realização das mesmas na cidade de Pelotas-RS. 
Quadro 1 - Início das atividades, número de edições e locais de realização dos eventos de PelotasRS pesquisados no Facebook até agosto de 2016

\begin{tabular}{|c|c|c|c|}
\hline Evento & $\begin{array}{l}\text { Início das } \\
\text { Atividades }\end{array}$ & $\begin{array}{l}\text { Número de Edições } \\
\text { até Agosto de } 2016\end{array}$ & Locais de Realização em Pelotas-RS \\
\hline $\begin{array}{l}\text { "Feira do Rolo } \\
\text { - Pelotas" }\end{array}$ & 2012 & $\begin{array}{l}10 \text { enquanto "Feira } \\
\text { Mercado das Pulgas" } \\
\text { e } 7 \text { enquanto "Feira } \\
\text { do Rolo - Pelotas" }\end{array}$ & $\begin{array}{l}\text { Largo do Mercado Público (primeiro local); } \\
\text { Travessa Conde Piratini (local atual); } \\
\text { Praça Coronel Pedro Osório (edição especial); } \\
\text { Parque da Baronesa (edição especial); } \\
\text { Praça da Alfândega (edição especial) }\end{array}$ \\
\hline "Fotroca" & 2014 & 11 & $\begin{array}{l}\text { Praça Coronel Pedro Osório (principal local de } \\
\text { realização); } \\
\text { Parque da Baronesa; } \\
\text { Praça da Rodoviária }\end{array}$ \\
\hline $\begin{array}{l}\text { "Piquenique } \\
\text { Cultural" }\end{array}$ & 2010 & 32 & $\begin{array}{l}\text { Praça Coronel Pedro Osório; } \\
\text { Praça Basílio da Gama; } \\
\text { Praça Tomaz Flores; } \\
\text { Praça Manoel Marques da Fonseca } \\
\text { Junior/Praça Modelo; } \\
\text { Praça São Marcos/Praça do Meio; } \\
\text { Praça Domingues Rodrigues/Praça da } \\
\text { Alfândega; } \\
\text { Praça Dr. Francisco Xavier; } \\
\text { Praça da Leocádia; } \\
\text { Praça da Rodoviária; } \\
\text { Praça Cipriano Barcellos/Praça dos } \\
\text { Enforcados; } \\
\text { Parque Dom Antonio Zattera; } \\
\text { Parque da Baronesa; } \\
\text { Praça da Liberdade; } \\
\text { Praça Conselheiro Maciel/Praça do Direito }\end{array}$ \\
\hline "Sofá na Rua" & 2012 & 38 & $\begin{array}{l}\text { Rua Almirante Tamandaré no } 608 \text { (primeiro } \\
\text { local); } \\
\text { Rua José do Patrocínio no } 8 \text { (local atual) }\end{array}$ \\
\hline
\end{tabular}

Fonte: Org. do Autor, 2016.

\section{Os Grupos de Trocas de Mercadorias em Pelotas}

No tocante aos grupos de trocas de mercadorias de Pelotas presentes no Facebook, foi realizado um levantamento quantitativo destes no SRS em novembro de 2015, de modo que foram utilizados os termos referentes às relações de troca: "Classificado(s)", "Compra(s), vende/a(s) e troca(s)", "Desapego(s)" e "Desapega", "Rolo(s)" e "Rolinho(s)", "Trato feito", "Brik/c(k)" e "Brecho(ó)", juntamente com a palavra "Pelotas", o que totalizou 296 grupos. Nestes foram encontradas discrepâncias quanto ao número de membros em cada grupo: 77 deles possuíam até 100 membros, outros 69 grupos possuíam de 101 a 500 membros, 34 grupos possuíam de 501 a 1.000 membros, 57 grupos possuíam de 1.001 a 5.000 membros, 26 grupos possuíam de 5.001 a 10.000 membros, 20 grupos possuíam de 10.001 a 20.000 membros, 10 grupos possuíam de 20.001 a 40.000 mil, e 3 grupos possuíam mais de 40.000 membros.

Foram encontrados grupos genéricos (os quais tiveram os seus nomes preservados nesta pesquisa conforme os originais encontrados no Facebook, independente de eventuais erros gramaticais, a fim de terem preservada a sua identidade e, também, de possibilitarem a sua correta identificação) que englobam as relações de trocas em geral, e grupos específicos, que tratam das relações de troca de um tipo específico de: a) mercadoria, como os grupos "Classificados Bicicletas Pelotas (Bicicletas, peças e acessórios) e "Desapegos só de Tenis Pelotas", por exemplo; b) localização (uma referência geográfica somada a de Pelotas), como os grupos "Classificados Laranjal Pelotas" e "brecho rolinhos trocas e vendas d bairro getúlio vargas de pelotas" (Laranjal e Getúlio Vargas são bairros pelotenses), por exemplo; c) profissão ou de uma identificação relacionada à profissão, como os grupos "Classificados dos Músicos de Pelotas" e "Classificados Odontologia Pelotas", por exemplo; d) gênero, como os grupos "Brechó Masculino (Pelotas/RS)" e o "Brechó 
Feminino (Pelotas/Rs), por exemplo; e vários outros tipos, como aqueles relacionados a idade ("Brecho Infantil Pelotas"), ao tamanho ("Brechó Plus Size Pelotas") e aos animais ("CLASSIFICADOS de ANIMAIS Pelotas-RS"), por exemplo. Essa tipologia pode ser simples, mas também pode ser combinada, elencando dois dos tipos observados como, por exemplo, o grupo "DESAPEGA MENINAS PELOTAS (GUABIROBA)" (Guabiroba é um bairro pelotense).

Para além da descrição dos grupos, foi aplicado um questionário online aos membros dos grupos pesquisados, a fim de investigar os seus perfis e as relações de trocas envolvidas. Foram selecionados os grupos considerados médios (de 1.001 a 20.000 membros) e grandes (acima de 20.000 membros), ou seja, 116 grupos. No entanto, em apenas 84 grupos o questionário pôde ser aplicado, pois era necessária a aprovação do administrador de cada grupo, o que não aconteceu em todos os casos. O resultado foi a obtenção de 126 respostas ao questionário. Este foi constituído por doze questões de múltipla escolha, com opções para respostas abertas, e organizado em duas partes, sendo que a primeira foi composta por quatro questões: 1) "Em qual faixa etária você se encontra?"; 2) "Seu gênero"; 3) "Qual a sua renda média mensal?"; e, 4) "Qual a sua escolaridade?".

Já a segunda parte do questionário continha oito questões: 1) "De quantos grupos de troca de mercadorias no Facebook você participa?"; 2) "Você já comprou alguma mercadoria nos grupos no Facebook?"; 3) "Você já vendeu alguma mercadoria nos grupos no Facebook?"; 4) "Você já trocou alguma mercadoria, sem o uso de dinheiro, nos grupos no Facebook?"; 5) "No caso afirmativo da questão acima, qual(is) o(s) motivo(s) que levou(aram) você a trocar alguma mercadoria sem o uso de dinheiro"; 6) "Que tipo(s) de mercadoria(s) você já comprou, vendeu e/ou trocou nos grupos no Facebook?"; 7) "Quando você negociou uma mercadoria com alguma pessoa nos grupos no Facebook, qual(is) local(is) vocês combinaram de se encontrar para trocá-la?"; e, 8) "Você já participou de algum tipo de encontro coletivo ou feira de compra, venda e troca organizado no Facebook, como o Piquenique Cultural, o Sofá na Rua, a Feira do Rolo ou o Fotroca?".

Primeiramente, sobre o perfil dos membros dos grupos que responderam o questionário, constatouse que a maioria são mulheres $(58,7 \%$ do total), a faixa etária mais presente nos grupos pesquisados é a de 25 a 29 anos, que contemplou 23,8\% dos entrevistados, seguido pela dos 15 aos 19 anos com 19,8\%, e dos 40 anos ou mais, com 19\% do total. Quanto à escolaridade, constatou-se que $62,7 \%$ dos indivíduos têm, ou tiveram, contato ou formação no ensino superior. Por fim, quanto a renda média mensal dos entrevistados, verificou-se que a maioria possui de um a três salários mínimos (38,1\% dos entrevistados), seguido pelos que não possuem renda $(25,4 \%$ do total) e dos que possuem até um salário mínimo (15,9\% do total).

No segundo momento, acerca das questões relacionadas à participação dos indivíduos nos grupos de trocas pesquisados e as especificidades das suas relações de trocas: 1) a quantidade de grupos de trocas que o indivíduo participa, o qual constatou-se que a grande maioria, 89,7\%, participa de três grupos ou mais, e que apenas $4 \%$ do total participa de somente um grupo; 2) a compra de mercadorias, praticada pelo menos uma vez por 75,4\% dos entrevistados; 3) a venda de mercadorias, realizada pelo menos uma vez por 67,4\% dos entrevistados; 4) a troca de mercadoria por mercadoria (MPM), sem o uso do dinheiro, foi realizada pelo menos uma vez por somente 26,2\% dos entrevistados; 5) no caso afirmativo da realização da troca de MPM foram questionados sobre os motivos que levaram a essa opção, na qual duas respostas foram escolhidas pela maioria dos entrevistados: "Não queria dinheiro, queria outra mercadoria em troca", e "Acredito que trocar é uma forma melhor de consumir do que a compra e venda"; 6) o tipo de mercadoria comprada, vendida ou trocada a partir dos grupos de trocas, que resultou num total de 190 itens citados pelos entrevistados, que foram diferenciados por categorias de vestuário, móveis, eletrônicos, beleza, automóveis e diversos. Esta questão, acerca do tipo de mercadoria, foi aberta a comentários aos entrevistados, o que resultou em dois depoimentos interessantes à pesquisa (referentes às respostas originais dos entrevistados, assim, eventuais erros gramaticais são de responsabilidade dos mesmos). O primeiro deles (Entrevistado A) diz: "Comprei bicicleta e um fogão a lenha. Já vendi roupas, calçados e brinquedos e trabalho com venda de artesanata praticamente só pelos grupos para complementar a renda mensal". Já o segundo (Entrevistado B) expôs: "Ja comprei moveis para montar a clínica veterinária de meu filho e uso para anunciar tanto a minha empresa como a clínica dele e por isto sou proprietária de mais de 10 grupos e sou membro de mais de 250 grupos". 
Quanto à espacialização das trocas iniciadas nos grupos desse tipo no Facebook, referente à penúltima questão do questionário, constatamos que estas foram realizadas pelos entrevistados principalmente através de duas maneiras: a) "Na residência de um dos indivíduos envolvidos na troca", apontadas por $50 \%$ dos entrevistados; e, b) "Em locais públicos e abertos, como em calçadas em frente a pontos de referência, praças, pontos de ônibus etc.", que contemplou 42,2\% dos entrevistados. Outras opções como "Em locais privados de uso público, como no shopping, em escolas e/ou universidades privadas, em estabelecimentos comerciais etc." e "Em locais públicos e fechados, como no Mercado Público Municipal, em escolas e/ou universidades públicas etc." também foram apontadas pelos entrevistados, porém em menor quantidade. Por fim, na última questão, 73,8\% dos entrevistados responderam que não participaram de nenhum tipo de encontro coletivo ou feira de trocas e $26,2 \%$ responderam que sim. Ou seja, é possível que aproximadamente um quarto dos entrevistados tenha frequentado algum dos eventos realizado em Pelotas pelo Piquenique Cultural, Feira do Rolo, Sofá na Rua e/ou Fotroca.

\section{RESULTADOS E DISCUSSÕES}

Ao fim da realização da pesquisa que resultou neste artigo, alguns pontos chamaram a atenção e mereceram destaque. Em relação aos eventos pesquisados, a partir da investigação quanto aos locais escolhidos para a realização das suas edições na cidade de Pelotas, pode-se concluir que o uso e ocupação dos espaços públicos urbanos ocorrem de forma dispersa, não sendo concentrada em um único local. Mesmo que dois deles não sejam itinerantes, ao todo foram identificados 18 locais diferentes, entre ruas, parques e praças (Figura 5 e Quadro 2). Há, dessa maneira, uma íntima relação entre os espaços virtual e concreto.

Figura 5 - Locais na cidade de Pelotas-RS em que ocorreram edições dos eventos pesquisados no Facebook.

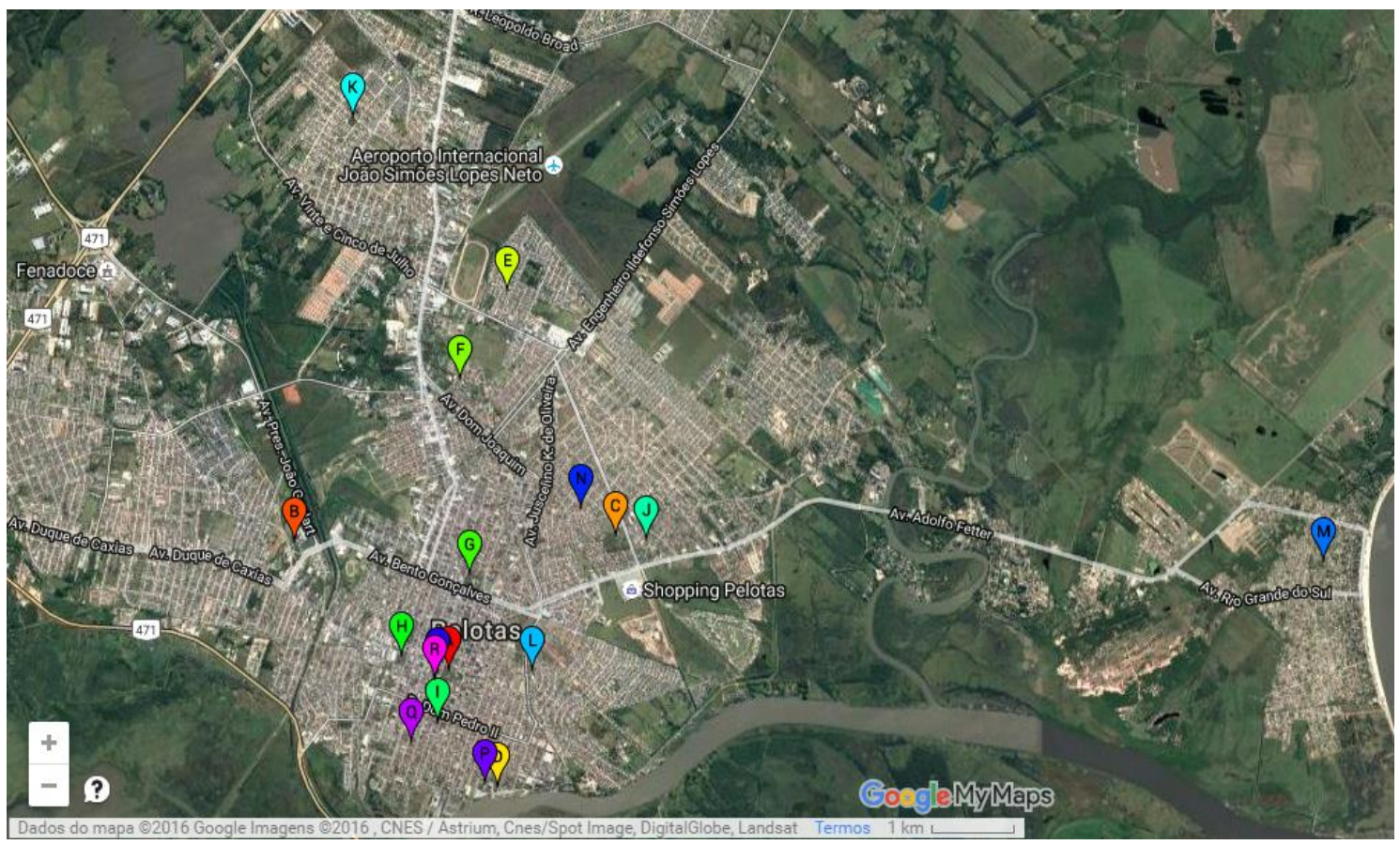

Fonte: Org. do Autor, 2016. 
Quadro 2 - Locais em que ocorreram edições dos eventos pesquisados no Facebook de PelotasRS conforme apontado na Figura 5

\begin{tabular}{|c|c|}
\hline Referência & Local \\
\hline A & Praça Coronel Pedro Osório, bairro Centro, Pelotas-RS \\
\hline $\mathbf{K}$ & Praça Basílio da Gama, bairro Três Vendas, Pelotas-RS \\
\hline E & Praça Tomaz Flores, bairro Três Vendas, Pelotas-RS \\
\hline $\mathbf{F}$ & Praça Manoel Marques da Fonseca Junior/Praça Modelo, bairro Três Vendas, Pelotas-RS \\
\hline M & Praça São Marcos/Praça do Meio, bairro Laranjal, Pelotas-RS \\
\hline D & Praça Domingues Rodrigues/Praça da Alfândega, bairro Porto, Pelotas-RS \\
\hline $\mathbf{L}$ & Praça Dr. Francisco Xavier, bairro Porto ( $\mathrm{N}^{\mathrm{a}} \mathrm{S} \mathrm{Sr}^{\mathrm{a}}$ Fátima/Várzea), Pelotas-RS \\
\hline $\mathbf{N}$ & Praça da Leocádia, bairro Areal, Pelotas-RS \\
\hline B & Praça da Rodoviária, bairro Fragata, Pelotas-RS \\
\hline $\mathbf{H}$ & Praça Cipriano Barcellos/Praça dos Enforcados/Praça do Pavão, bairro Centro, Pelotas-RS \\
\hline G & Parque Dom Antonio Zattera, bairro Centro, Pelotas-RS \\
\hline C & Parque da Baronesa, bairro Areal, Pelotas-RS \\
\hline $\mathbf{J}$ & Praça da Liberdade, bairro Areal, Pelotas-RS \\
\hline I & Praça Conselheiro Maciel/Praça do Direito, bairro Centro, Pelotas-RS \\
\hline 0 & Travessa Conde de Piratini, bairro Centro, Pelotas-RS \\
\hline $\mathbf{P}$ & Rua José do Patrocínio, no 8 , bairro Porto, Pelotas-RS \\
\hline $\mathbf{Q}$ & Rua Almirante Tamandaré, no 608 , bairro Centro, Pelotas-RS \\
\hline $\mathbf{R}$ & Largo do Mercado Público Central, bairro Centro, Pelotas-RS \\
\hline
\end{tabular}

Fonte: Org. do Autor, 2016.

Ao observarmos os desdobramentos das relações de trocas iniciadas no espaço virtual e concretizadas no espaço físico, na cidade de Pelotas-RS, a distribuição dos locais onde se realizaram as edições dos eventos pesquisados, constatamos que estes não estão presentes apenas na região central. Esse fato é de grande importância, visto que traz o olhar para os outros lugares da cidade de Pelotas-RS, os bairros que, muitas vezes, são pouco ou não são conhecidos por quem não reside neles. Desse modo, quando as edições dos eventos chamam a atenção para esses locais, elas possibilitam uma outra visão dos mesmos, inclusive para aqueles que não chegam a participar das edições dos eventos, pois aqueles que veem a página do evento no Facebook ou são convidados pelos amigos passam a saber que existe um lugar para lazer e trocas que não esteja necessariamente no centro; e aqueles que residem próximo ao local em que os eventos ocorrem, ou que estejam de passagem, mesmo sem terem conhecimento prévio da realização do evento, podem passar a ter uma perspectiva diferente daquele lugar, por exemplo. Os lugares ganham novos significados.

Para além dos objetivos e locais de cada evento, bem como o seu número de edições e ano de criação, também destacaram-se as dinâmicas de trocas presentes em cada evento pesquisado. Dois deles apresentaram as trocas materiais como parte intrínseca das suas dinâmicas, a "Feira do Rolo" e o "Fotroca", mesmo que outras relações possam se desenvolver, como trocas de conhecimentos, técnicas, experiências e divulgação de trabalhos dos participantes. Os outros dois eventos, o "Piquenique Cultural" e o "Sofá na Rua", possuem dinâmicas essencialmente de cunho artístico e cultural, nas quais as trocas apresentam-se ora de forma material, a partir da presença de expositores e vendedores de comidas, bebidas, artesanatos e serviços variados, e ora de forma imaterial, através da troca de conhecimentos, experiências, técnicas e afetos entre os participantes. Também chama a atenção a dinâmica de troca de MPM, sem o uso do dinheiro, e o objetivo de parte dos participantes dos eventos pesquisados, no que refere-se à preocupação ambiental atribuída às trocas: a ideia de repensar o consumo e o descarte de mercadorias, que tem sido apontado como potencialidades na chamada economia colaborativa.

Quanto aos grupos de trocas de mercadorias, constatou-se que os seus membros são em maioria jovens de 15 aos 29 anos, com renda de até três salários mínimos e que tiveram contato com o ensino superior, o que pode apontar para a participação acentuada de um público universitário, considerando a realidade de Pelotas enquanto polo de ensino superior na região sul do estado. No que tange às mercadorias e suas dinâmicas de trocas, percebe-se, a partir dos depoimentos dos Entrevistados $\mathrm{A}$ e $\mathrm{B}$, bem como das respostas das demais questões obtidas a partir do questionário aplicado, a importância que esses grupos têm na dinâmica econômica da vida de muitos indivíduos e famílias, e que para muitos trata-se de um negócio eficaz e significativo.

Caminhos de Geografia Uberlândia - MG $\quad$ v. 21, n. 73 $\quad$ Mar/2020 p. 116-130 Página 128


São inseridas nas dinâmicas de trocas desde pequenas mercadorias como roupas e livros até automóveis e mesmo imóveis, que refletem diretamente na concretização das trocas iniciadas no espaço virtual, pois a depender da natureza da mercadoria a troca se efetivará em locais públicos ou na casa de um dos envolvidos na troca - quando a mercadoria é um móvel como um sofá, por exemplo, a troca tende a ser realizada na casa do comprador ou do vendedor, implicando a necessidade de um meio de transporte para a entrega ou retirada da mercadoria. No caso das trocas realizadas em espaços públicos, é possível que essa opção seja uma das mais escolhidas pelo fato de tratarem-se de locais populares e de fácil acesso, bem como a possibilidade de oferecer um local neutro que pode, em muitos casos, traduzirem-se em locais mais seguros, visto que contarão com a presença de um fluxo constante de pessoas.

Há, assim, dois resultados gerais sobre as transformações recentes no comércio e no consumo. 0 primeiro refere-se ao uso acentuado, tanto em intensidade quanto em importância, das TICs e também dos SRS nas relações comerciais atuais. Por fim, o segundo trata da intensa e dialética relação entre os espaços virtual e concreto, pois ao passo que o Facebook surge como uma importante ferramenta virtual de apropriação popular que proporciona desdobramentos de suas atividades no espaço concreto, ao mesmo tempo se sobressai a importância desse espaço no contexto da realização dos eventos e na concretização das trocas iniciadas no Facebook, nesse caso nos desdobramentos no espaço urbano na cidade de Pelotas.

\section{CONSIDERAÇÕES FINAIS}

Considerando a rapidez e fluidez das dinâmicas atuais identificadas aqui como parte do que se entende como hipermodernidade, faz-se necessário investigar e analisar a importância das TICs em tal contexto histórico, especialmente através da Geografia. Ao buscarmos o entendimento dessas novas relações a partir do olhar geográfico, percebemos que além de complexas elas são também contraditórias, pois ao passo que podem aproximar os indivíduos, elas também podem distanciá-los, quando estes não dispõem de acesso aos aparatos tecnológicos necessários. 0 espaço físico, concreto, embora num primeiro momento possa não parecer ser protagonista, apresenta-se como fundamental ao buscarmos a essência dos processos. É preciso, dessa maneira, atentar aos grandes movimentos globais, intermediados em grande medida pelas TICs, da mesma forma que é preciso o olhar atento às relações locais, pois são nestas que elas se concretizam.

Assim, destacamos que nossa pesquisa representa apenas uma pequena amostra do grande potencial presente na mediação do Facebook, e demais SRS e TICs, para as possíveis relações entre os espaços, virtual e concreto, nas relações sociais e de comércio e consumo. Buscamos, desde o início, desenvolver questões e buscar respostas que pudessem proporcionar um melhor entendimento das transformações em curso, especialmente para o campo da Geografia, o que nem sempre constitui uma tarefa fácil, visto que tais transformações se dão muito rapidamente, porém necessária.

\section{AGRADECIMENTOS}

Agradeço ao Conselho Nacional de Desenvolvimento Científico e Tecnológico (CNPq) pela bolsa concedida para a realização da pesquisa de mestrado da qual resultou este artigo.

\section{REFERÊNCIAS}

ASCHER, F. Novos Princípios do Urbanismo. Lisboa: Livros Horizonte, 2010.

CATALANI, L.; KISCHINEVSKY, A.; RAMOS, E.; SIMÃO, H. E-commerce. Rio de Janeiro: Editora FGV, 2004.

FACEBOOK. Community Update. Publicado em 27 abr. 2016. Disponível em: $<$ https://www.facebook.com/photo.php?fbid=10102803309152781\&set=pb.4.2207520000.1551823848.\&type=3\&theater >. Acesso em 10 mai. 2018. 
FELIPINI, D. Facebook-Commerce. Publicado em 14 dez. 2015. Disponível em <http://www.ecommerce.org.br/facebook-commerce> Acesso em 10 mai. 2018.

HARVEY, D. Condição Pós-Moderna. São Paulo: Ed. Loyola, 2004.

IBGE - Instituto Brasileiro de Geografia e Estatística. Censo 2010. Disponível em < https://cidades.ibge.gov.br/brasil/rs/pelotas/panorama> Acesso em 10 mai. 2018.

LÉVY, P. Cibercultura. São Paulo: Ed. 34, 1999.

O que é o Virtual? São Paulo: Ed. 34, 2011.

LIPOVETSKY, G.; CHARLES, S. Os Tempos Hipermodernos. São Paulo: Barcarolla, 2004.

MAFALDO, C. F. Um estudo sobre as formas de interação e trocas evidenciadas no Piquenique Cultural, Pelotas - RS. 2009. Trabalho de Conclusão de Curso (Trabalho de Conclusão de Curso de Ciências Sociais) - Instituto de Sociologia e Política, Universidade Federal de Pelotas, Pelotas, 2013.

MITCHELL, W. J. E-topia: a vida urbana, mas não como a conhecemos. São Paulo: Editora Senac São Paulo, 2002.

ORTIGOZA, S. A. G.; RAMOS, C. S. A Geografia do Comércio Eletrônico (e-commerce) no Brasil: O Exemplo do Varejo. Geografia. Rio Claro, SP, v. 28, n. 1, p. 63-81, 2003.

PARAISO, G. J. B. O e-commerce nas redes sociais: estudo sobre os desdobramentos do comércio eletrônico na atualidade. Bocc: Biblioteca on-line de ciências da comunicação, 2011. 16 p. Disponível em: <http://www.bocc.ubi.pt/pag/paraiso-gustavo-o-e-comerce-nas-redes-sociais.pdf>. Acesso em 10 mai. 2018.

RECUERO, R. Redes sociais na Internet. Porto Alegre: Sulina, 2009.

SANTOS, M. A Natureza do Espaço: Técnica e Tempo, Razão e Emoção. São Paulo: Edusp, 2002.

STATISTA. Number of Facebook users worldwide 2008-2019. Publicado em 9 ago. 2019. Disponível em: <https://www.statista.com/statistics/264810/number-of-monthly-active-facebookusers-worldwide/> Acesso em 04 nov. 2019.

TEIXEIRA, T. Comércio eletrônico: conforme o Marco Civil da Internet e a regulamentação do ecommerce no Brasil. São Paulo: Saraiva, 2015.

Recebido em: 15/03/2019

Aceito para publicação em: 19/08/2019 